\title{
The school setting: an opportunity for the implementation of dietary guidelines
}

\author{
Carmen Pérez-Rodrigo ${ }^{1 *}$, Knut-lnge Klepp ${ }^{2}$, Agneta Yngve ${ }^{3}$, Michael Sjöström ${ }^{3}$, Lynn \\ Stockley ${ }^{4}$ and Javier Aranceta ${ }^{1}$ \\ 'Community Nutrition Unit, Bilbao Department of Public Health, Luis Brinas 18; 3 Planta, E 48013 Bilbao, Spain: \\ ${ }^{2}$ Institute for Nutrition Research, University of Oslo, P O Box 1046, Oslo, Norway: ${ }^{3}$ Unit for Preventive Nutrition, \\ Department of Biosciences, Karolinska Institutet, 14157 Huddinge, Sweden: ${ }^{4}$ Food \& Nutrition Consultant, \\ Timberland, Mill Hill, Brockweir, nr Chepstow, Gloucestershire, NP16 7NN, UK
}

\begin{abstract}
Nutrition, physical activity and health related promotion programmes in schools have developed into a mature field of research over the past decades. A number of success factors have been identified and evidence-based interventions have been performed. However, the school setting as an arena for evidence-based health promotion programmes, is still not used to its full potential. Schools provide an excellent arena for reaching large segments of the population, such as young people, school staff, families and the surrounding community.

There is a need for an overview regarding the current status of nutrition, physical activity, related health as well as support structures in the EU member states. Based upon such an analysis, a consensus report should be written, pointing out the major problems at hand. Self-assessment tools for national as well as for school level should be produced, in order to guide changes, but also to include an element of continuous assessment of change, for evaluation purposes.
\end{abstract}

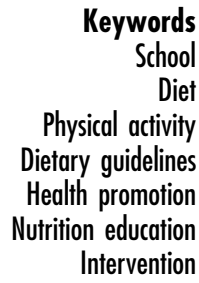

Beginning prevention early by improving lifestyles and focusing on healthful food choices within the context of the total diet has the potential for a major impact on the future of adult chronic diseases ${ }^{1}$. Healthy eating and regular physical exercise help young people to feel good, perform better at school and avoid developing risk factors which may lead to major chronic diseases and premature death. A relevant education in nutrition, physical activity and health, is a key element to promoting lifelong healthy eating and exercise behaviours. In order to successfully promote diet- and physical activity-related health, other factors such as effective policies that facilitate a positive school environment are required ${ }^{2,3}$.

The school setting provides a valuable opportunity to influence health through policy measures, education and food provision. Schools provide the most effective and efficient way to reach a large segment of the population, including young people, school staff, families and community members.

\section{Evidence base}

Major early literature reviews of nutrition education programmes in school settings ${ }^{4}$ highlighted the need for more and better research in this field. Much of the early research in school health education focused on knowledge-based classroom programmes. Many knowledge-based studies did not consider the multiple factors influencing eating behaviours, i.e. interactions between individuals and their social and physical environments ${ }^{4,5}$. Nutrition education in general and school-based education in particular has however developed into a mature field of research over the past decades.

A review of the research studies conducted during the 1980s found that there had been a dramatic increase in school-based nutrition education research, with improved research designs and methodologies compared with previous reviews ${ }^{6}$. The importance of making nutrition messages developmentally appropriate and delivering specific behavioural advice to help children make informed food choices has been emphasised ${ }^{7}$.

Lytle and Achterberg $^{7}$ identified several elements conducive to successful nutrition education programmes:

1. Educational strategies directly relevant to a behavioural focus and theory driven;

2. Adequate time and intensity for the intervention is provided;

3. Family involvement enhances the effectiveness of programmes for younger children;

4. Incorporation of a self-evaluation or a self-assessment and feedback is effective in interventions for older children; 


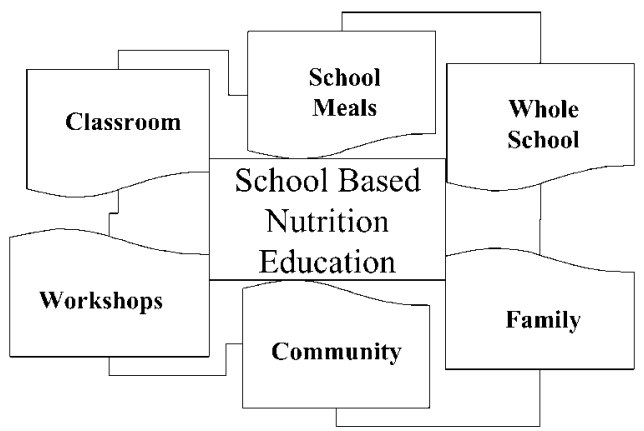

Fig. 1 Components of school-based nutrition education

5. Include interventions in the school environment;

6. Interventions in the larger community can enhance school nutrition- and health education.

Other authors' reviews have led to similar conclusions $^{8,9}$. Effective programs in diverse communities must be tailored to community needs and take into consideration factors concerning individuals, such as cultural background and equity aspects. Community assessment helps to identify the cultural traditions and beliefs as well as skills and resources required.

Several successful programmes include a multi-component prevention model, beginning in elementary school and extending to high school. Figure 1 shows components to be considered in school-based nutrition education. Most of these programmes include an environmental element in the strategy influencing the quality of the food provided by school meals ${ }^{10-12}$ and involve collaboration with different partners.

The first school-based studies focusing specifically on vegetables and fruits (as part of the 5-a-Day project in the USA) have been recently published. Perry and colleagues reported a significant increase in observed lunchroom intake of vegetables and fruit, and an overall increase in reported fruit consumption, but not for vegetable consumption, among fourth and fifth graders ${ }^{13}$. Similarly, a $14 \%$ increase in the usual daily servings of vegetables and fruits was observed for high school programmes, but this effect disappeared by 3rd year of follow-up ${ }^{14}$. Reynolds et $a l .{ }^{15}$ reported increased consumption of daily servings of fruit and vegetables in fourth graders and their parents.

In Europe, WHO's Health Promotion Initiative ${ }^{16}$ has inspired a number of school-based actions, including the European Network of Health Promoting Schools ${ }^{17}$ and nutrition specific efforts ${ }^{18,19}$. These use a comprehensive health promotion approach, with a focus on empowerment. This is applied to both an individual (student) level through personal skills development, as well as on a local (school and community) level through healthy policies and supportive environments. Comprehensive school health programmes within the Healthy School framework can therefore be described as student-centred, involving

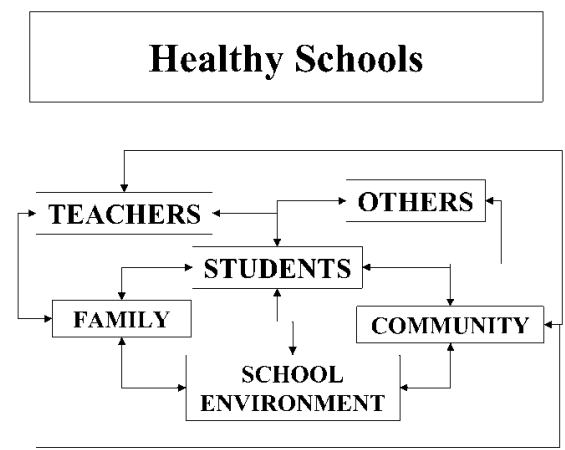

Fig. 2 Framework for student-centered comprehensive school health programmes in the Healthy School concept

all members of the school and focusing on processes leading to changes in school policies and school environment ${ }^{20}$ (Fig. 2).

Educational strategies include efforts to increase health awareness, communication and skill building. Policy strategies are those laws and regulations, formal and informal rules and understanding adopted on a collective basis to guide individual and collective behaviour. These include healthy policies designed to encourage healthful actions. Environmental strategies are measures that alter or control the legal, social, economic and physical environment, thus contributing to a more supportive environment of health and well-being by creating opportunities for action by removing barriers to following a healthy $\operatorname{diet}^{21}$ (for example, increasing accessibility to fruit and vegetables in the school).

Although, on the whole, young people are more active than adults are, many have a sedentary life-style. There is a particularly sharp decline during the teenage years. The Centre for Disease Control and Prevention (CDC) recently reviewed physical activity among children and adolescents and produced guidelines to promote lifelong physical activity ${ }^{22}$. Based on the available evidence they concluded that efforts to promote physical activity among students should be part of a co-ordinated, comprehensive school health programme. In particular, programmes should involve families, and be supported by the local community.

A multidisciplinary approach is important, including health education, health services, social welfare and other school support services. Their recommendations for physical activity have been incorporated, where relevant, in the later section on proposals and recommendations for strategies in the school setting. Self-assessment tools for schools which consider elements involving nutrition and physical activity can be very useful to stimulate action and identifying opportunities in the school setting. Ideas from the materials developed by the CDC have been incorporated into this document ${ }^{23,24}$.

It is important to emphasise that the health of communities not only depends on the health of individuals, 
but also on whether the physical and social aspects of communities enable people to adopt healthy lifestyles.

The benefits of breastfeeding for mother and child are well documented. It is of vital importance to address this issue in schools as part of comprehensive health education programs, since breastfeeding is clearly correlated to age and educational level, where young, lower educated mothers breastfeed less ${ }^{25,26}$. Young mothers who have not been breastfed themselves may never have been exposed to positive breastfeeding role models in their home environment.

\section{Diversities of EU Member States}

There is a wide range of approaches to health, physical and nutrition education in the different EU Member states. In some countries, to a certain extent, nutrition education is part of the School Curriculum. A survey carried out in all 15 EU member states, Iceland, Norway and Switzerland, during the testing process of a Nutrition Education Guide for Health Promoting Schools ${ }^{18}$ found no official policy or overall national policy in many EU countries. Even in those countries where it is included in the school curriculum, it is not considered as a subject in itself. There are also a variety of professionals (teachers, educators, nutritionists, school health people, public health workers, physicians and so on) with a responsibility for delivering nutrition education programmes. Although teachers are involved in nutrition education projects very often, basic and continuing education teacher training in nutrition is frequently absent or poor.

Nutrition education programmes are implemented to varying extents in primary and secondary schools across European countries, in many cases without continuity. The same diversity applies to school meals. Whilst in some countries every school provides a warm meal for the students, in other countries there are no school meals. In a few countries there are some regulations regarding the quality of the menu offered in school meals, in terms of nutrient content or consistency with national dietary guidelines. In most places existing regulations refer only to hygienic aspects of food quality. Overall there is a wide variation within and between countries, as well as between age groups in how food is made available e.g. canteens, tuck shops, vending machines and so on.

\section{Suggested strategies and recommendations for the implementation of dietary guidelines in the school setting}

\section{At a European level: Assessment of the current situation}

\section{Rationale}

Identifying problems and needs is the very first step in any planning attempt. It is required to thoroughly assess the current situation, both at European and national level, considering dietary behaviours and physical activity patterns of European children and young people as well as factors influencing those patterns; school policies related to food, nutrition and physical activity; nutrition, health and physical education in schools; school nutrition and health services; and family and community involvement in schools.

This compilation can include linking of the existing data from WHO Youth Survey ${ }^{27}$ to other existing data regarding nutritional and physical activity indicators as well as to data on related, modifiable determinants for health at European level like the European Youth Heart Study $^{28}$ or other sources at country level ${ }^{29}$. E.g. school meals and the existence of other support systems, to ensure equity and early identification of risk groups and risk schools.

\section{Strategies}

Complete existing school survey data by using additional sources of information:

i) EU monitoring programme and other existing sources of information in member states regarding food consumption patterns and determinants of eating behaviour. ii) Data on physical activity/inactivity for children and youth.

iii) Data on the existence, use and quality control of school meal programmes/school food service in member states.

iv) Data on level, time dedicated, quality control of physical education lessons in schools curriculum in EU member states.

v) Data on nutrition education in schools, considering time dedicated, quality control, support, curriculum content and implementation.

\section{At a European level: Reinforce mutrition education and physical activity in primary and secondary schools in all EU Member states}

\section{Rationale}

The school setting provides a valuable opportunity to influence health through policy measures and education $^{30,31}$. Schools provide the most effective and efficient way to reach large portions of the population, including young people, school staff, families and community members. Students can be reached at influential stages in their lives and over a long period of time. Selfassessment and planning tools like the ones developed by the $\mathrm{CDC}^{23,24}$ and Andrien et al. in Europe ${ }^{31}$ can be very useful to identify gaps and provide process indicators.

\section{Strategies}

Establish a European expert group, in collaboration between the European major players, for example the 
European Network of Health Promoting Schools within $\mathrm{EC} / \mathrm{EU} / \mathrm{WHO}$, the nutrition education unit within FAO Rome, and the European Network of Public Health Nutrition with the aim to:

(i) Develop strong European consensus documents on the importance of school programmes for developing a healthy lifestyle, also describing the current situation assessed as outlined above. This document should specifically highlight the issue of equity in this regard, within and between countries.

(ii) Develop a self-assessment kit in two parts:

The first designed to assess the existing national situation (for countries). This self assessment tool should investigate national regulations/systems/consensus documents in countries, such as:

Health education curriculum for schools, including nutrition, breastfeeding, school meals and physical education, health education elements in training of teachers and of school staff, school health care provisions, school meal provisions, recommendations/quality assurance systems. Furthermore, rules regarding transportation to/from schools that provide support/constraints to physical activity, national consensus documents/recommendations in relevant areas supporting nutrition education and physical activity in schools, rules that regulate school environment in ways that restrict or support physical activity during breaks, data on health status and health promotion of school staff, including work environment analyses if available, should be included. They should also include an element of assessing community involvement, such as the existence and function of parent-teacher associations. National action plans or other Health Policy documents at national or regional levels, which include elements, related to schools, nutrition and physical activity.

The second self-assessment kit would be created for self-assessment purposes in schools, describing the existing situation. This self-assessment tool should be prepared as a support for schools in monitoring their own situation, and as a basis for action. It could contain elements like:

Policy and environmental assessment (local policy documents, physical environment, transportation facilities and regulations locally), health education assessment (nutrition elements, breastfeeding and physical education, as well as anatomy, work physiology etc, coverage, time spent, training of teachers), school meal provisions (data regarding cost, crude consumption data, quality assurance, level of integration of school meal staff with teaching staff, eating environment and time dedicated to eating etc.), school health services (type and extent, integration of staff and staff training), health promotion for staff (type and extent), family and community involvement (NGOs, social services, retailers, sports clubs, wildlife clubs, primary health care, local health planners etc) (iii) These two self-assessment tools should then be tested and used to further analyse the situation on national level and in a representative number of schools.

(iv) Disseminate the tools to member states after consultations and testing

(v) Provide funding for pilot projects including an EU dimension and elements of sustainability

(vi) Arrange annual conferences providing an evidence-based approach to the whole issue of school physical activity, nutrition including school meals, breastfeeding promotion and general health promotion.

\section{At a national level: Implement a curriculum for nutrition and physical activity education from pre- school to secondary schools}

\section{Rationale}

This curriculum should provide students with the knowledge and skills required to be 'nutrition and health literate ${ }^{, 7,18,22,30}$. A comprehensive health education approach is important, particularly linking nutrition and enjoyable participation in physical activity. Evidence shows that long lasting programmes, either inside or outside the classroom, have been more effective and achieve sustained changes ${ }^{7,9,32,33}$. Dimensions related to healthy eating and active lifestyle to be considered in the school curriculum are shown in Fig. 3. It is of utmost importance also to integrate issues regarding breastfeeding into the curriculum ${ }^{25,26}$.

\section{Strategies}

i) Advocate nutrition education, physical activity and integrated school food services among those responsible for curriculum development.

ii) Build multidisciplinary groups of experts to facilitate this task, including school food service, education and health promotion experts.

iii) Encourage the construction of a sequential curriculum for nutrition education in each country, building on

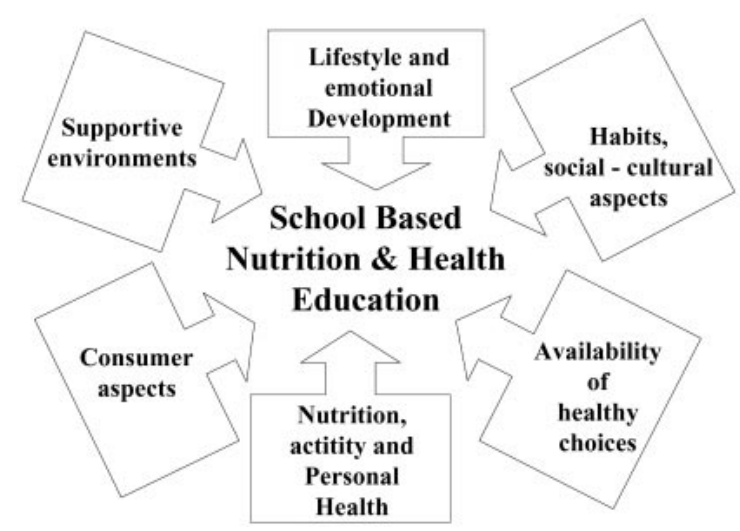

Fig. 3 Dimensions related to healthy eating and active lifestyle to be considered in the school curriculum 
already existing experiences and materials. It should be developmentally appropriate and culturally relevant (in terms of region, local and ethnic group differences) ${ }^{34}$. The curriculum should be behaviourally oriented, aiming to provide students with the required knowledge, enable skills development, encourage self-efficacy and behaviour change in order to enable students to adopt a healthful diet and physical activity levels according to dietary guidelines ${ }^{21,30,35}$.

iv) Stimulate cross-curricular development of nutrition and physical activity education within other subjects' objectives.

v) Allocate time and resources to perform activities aimed at achieving nutrition education learning objectives in schools.

vi) Allocate enough time and resources to encourage children to be physically active in schools

vii) Encourage research on teaching methods and approaches, which will help the achievement of nutrition education objectives

viii) Support the development of suitable teaching materials, which include active learning methods.

\section{At a national/regional/local level: Integration of school meals in the educational process}

\section{Rationale}

School meals provide a valuable opportunity for nutrition education. Food provided at schools should be nutritionally adequate and consistent with classroom messages ${ }^{36,37}$. Staff dealing with school meals should be properly trained, supported and integrated with teaching staff.

\section{Strategies}

i) Make healthy food choices available in the school for children, teachers and others in the school. This is particularly important when school meals are based on a single menu offer. In this situation the menu should be carefully planned to be nutritionally adequate and consistent with dietary guidelines. This should also apply to vending machines, tuck shops and other places in the school where food is available.

ii) Develop school nutrition policies for the provision of food in schools.

iii) Provide training opportunities and support for kitchen or school meals personnel in their important work.

iv) Encourage involvement of kitchen-school meals personnel in nutrition education activities.

v) Provide families with adequate information regarding school meals and facilitate occasions where parents can take part in the school.

vi) Integrate physical education in the overall educational process in schools.

vii) Provide families with adequate information about physical education activities in schools and encourage parents' involvement.

\section{At a national/regional/local level: Training for teachers and others involved in nutrition education and physical activity promotion}

\section{Rationale}

Adequate training contributes to increased awareness and in motivating teachers and educators to support healthy lifestyles. It can also contribute to enhancing teachers' self-efficacy and will provide them with adequate knowledge and skills to implement activities related to the dietary guidelines ${ }^{38,39}$.

\section{Strategies}

i) Encourage initial (pre-service or basic) teacher training in nutrition and health.

ii) Provide teachers and others involved with opportunities for continuing education in the field of nutrition and physical activity.

iii) Provide support and advice for teachers and other professionals involved in school nutrition education programmes and in promotion of physical activity.

\section{At a national/regional level: Involve School Health Services in the planning and implementation pro- cess of programmes related to the promotion of bealtby eating and physical activity for children as well as for school staff}

\section{Rationale}

Schools should provide nutrition services as an integral component of school work, with health services as one important partner. Co-ordination and partnership among all members of the school community ${ }^{40}$ is a pre-requisite to develop consistent healthy school policies supportive to healthy nutrition and enjoyable physical activity.

\section{Strategies}

i) Increase awareness of the relevance of healthy eating and physical activity for growth, development, cognitive performance and health promotion of children and young people among people involved in school health services. ii) Provide opportunities for continuing training of people working in school health services.

iii) Stimulate multidisciplinary collaboration between people responsible for public health nutrition and health promotion programmes, school health services, and educators in order to effectively implement school nutrition education.

iv) Use the school health services to - in collaboration with other school staff - design and implement school staff health promotion initiatives. 
Table 1 Summary of recommendations to facilitate implementation of dietary guidelines in the school setting; described according to level of action

\begin{tabular}{|c|c|c|c|c|}
\hline \multirow[b]{2}{*}{ Suggested strategies and recommendations } & \multicolumn{4}{|c|}{ Level of action } \\
\hline & European & National & Regional & Local \\
\hline 1 Assessment - monitoring of the current situation & 口 & $\square$ & $\square$ & $\square$ \\
\hline $\begin{array}{l}2 \text { Reinforce nutrition education and physical activity in primary } \\
\text { and secondary schools in all EU Member states }\end{array}$ & $\square$ & & & \\
\hline $\begin{array}{l}3 \text { Implement a curriculum for nutrition and physical activity } \\
\text { education from pre-school to secondary schools }\end{array}$ & & $\mathbf{\square}$ & & \\
\hline 4 Integration of school meals in the educational process & & $\mathbf{\square}$ & $\mathbf{a}$ & $\mathbf{a}$ \\
\hline $\begin{array}{l}5 \text { Training for teachers and others involved in nutrition } \\
\text { education and physical activity promotion. }\end{array}$ & & $\mathbf{\square}$ & $\mathbf{\square}$ & $\mathbf{\square}$ \\
\hline $\begin{array}{l}6 \text { Involve School Health Services in the planning and } \\
\text { implementation process of programmes related to the } \\
\text { promotion of healthy eating and physical activity }\end{array}$ & & $\mathbf{\square}$ & $\square$ & \\
\hline $\begin{array}{l}7 \text { Create a friendly school environment which contributes to } \\
\text { making the healthy food choice available and easy and } \\
\text { stimulates the practice of physical activity }\end{array}$ & & & $\square$ & $\square$ \\
\hline $\begin{array}{l}8 \text { Encourage family and community involvement in school } \\
\text { nutrition education and physical activity programmes. }\end{array}$ & & & $\mathbf{\square}$ & $\square$ \\
\hline
\end{tabular}

Suggested level of action for each recommendation/strategy.

\section{At a regional/local level: Create a friendly school environment, which contributes to making the bealthy food choice available and easy and stimu- lates the practice of physical activity}

Rationale

Policies formulated at European and national level must support the long-term benefits of healthy eating and physical activity. These overall policies are important elements to create healthy school environments, but effective implementation and success requires the development of regional and local policies involving all members of the community ${ }^{20,40}$.

\section{Strategies}

i) Allocate enough time and resources to physical activity in the schools.

ii) Integrate elements of enjoyable outdoor, wildlife activities into the school year according to seasonal and cultural variations.

iii) Provide children, teachers and others with tips to be physically active safely travelling to school and also in the school.

iv) Provide children, teachers and others with a pleasant room, good atmosphere and plenty of time to enjoy healthy food in the school, either food provided by the school or brought from home.

v) Implement if possible, a school garden; providing opportunities for children to learn how to grow their own food and to taste and prepare vegetables, fruits and berries grown in the school yard or indoors, depending on seasonal variations, summer vacation and climate. vi) Integrate physical education in the overall educational process in schools.

\section{At a regional/local level: Encourage family and community involvement in school nutrition educa- tion and physical activity programmes}

\section{Rationale}

The emphasis on environmental and behavioural factors in successful school based physical activity and nutrition interventions highlights the importance of involving parents and other community members ${ }^{41-43}$. Evidence clearly supports this ${ }^{44-46}$.

\section{Strategies}

i) Inform families about initiatives to be developed in the school to promote healthy eating and physical activity, including school policies, classroom projects and school meals

ii) Invite breastfeeding mothers to the classroom, to ensure that all children are exposed to breastfeeding women. (Could be arranged through child health care services)

iii) Invite families to take part in school or out-of-school activities

iv) Encourage participation of parent-teacher associations in designing school activities and programmes.

v) Provide families with tips for healthy food choices for children

vi) Link to community programmes for providing plots for hobby gardening for families without gardens.

vii) Encourage the participation of food stores, sports goods and wildlife gear stores in the school work, in demonstrations and activities

viii) Encourage collaboration with sports clubs and wildlife clubs such as scouts, ornithologist clubs etc in the schoolwork, in excursions and activities.

ix) Provide families with adequate information about 
physical education activities in schools and encourage parents' involvement.

Table 1 summarises suggested levels of action for each of the above strategies and recommendations.

\section{Evaluation}

Intervention strategies should be carefully planned and followed up. Implementation is a complex and usually slow development. Evaluation of progress must be sensitive and involve collaboration of all participants. Evaluation is concerned with assessing the effectiveness and efficiency of interventions. However it is important to follow the progress towards the major goals and to use the results of the evaluative process to encourage and enhance the strategy.

In the European context, at national and local level, it would be interesting to consider using the suggested selfassessment tools, on country level and schools level. Evaluation of impact as well as outcomes and process should in that case be integrated into the tool kits. A system for further monitoring of dietary intake and physical activity in children and youth should be established. This could be used for assessing the outcome of major policy changes on national level.

\section{Conclusions}

It is of vital importance to assess the current status of nutrition, physical activity and support structures in the Member Countries. A European Expert Group should use the data achieved by this initial stage of action, in order to publish a Status report. This should be combined with a system for monitoring change as well as a Consensus report regarding implications for health and recommendations for action.

In order to facilitate practical approaches as well as to introduce an element of empowerment, self-assessment tools should be produced, for national and school level respectively. These tools should be designed to guide changes, and also to include an element of continuous assessment of change, which can be used for evaluation purposes.

In the further work, it is important not only to look at the classroom curriculum aspect of nutrition, breastfeeding, physical activity and health education, but to look at the

- school structures as such and partnerships in the local community

- health of school staff and integration of physical education and school meals staff with other staff

_ involvement of the family in school activities.

Since all these elements should be covered in the selfassessment tools, we can thereby provide a practical and inspiring tool for action.

\section{References}

1 Nicklas TA, Webber LS, Johnson CC, Srinivasan SR, Berenson GS. Foundations for health promotion with youth: a review of observations from the Bogalusa Heart Study. J. Health Educ. 1995; 26(2 Suppl): 18-26.

2 CDC. Guidelines for school and community health programs to promote lifelong physical activity among young people. $M M R W$ 1997; 46: 1-6.

3 Hornak L, Block G, Lane S. Influence of selected environmental and personal factors on dietary behavior for chronic prevention; a review of the literature. J. Nutr. Educ. 1997; 29: 306-12.

4 Saylor KE. Nutrition education research: Fast or famine? In: Coates TJ, Petersen AC, Perry CL, eds. Promoting adolescent health. A dialog on research practice. New York: Academic Press, 1982: 355-80.

5 Birch LL, Fisher JO. Development of eating behaviors among children and adolescents. Pediatrics 1998; 101(Suppl): 53949.

6 Contento IR, Manning AD, Shannon B. Research perspective on school-based nutrition education. J. Nutr. Educ. 1992; 24: 247-60.

7 Lytle LA, Achterberg CL. Changing the diet of America's children: what works and why? J. Nutr. Educ. 1995; 27: 25060 .

8 Contento IR (ed). The effectiveness of nutrition education and implications for nutrition education policy, programs and research - a review of research. J. Nut. Educ. 1995; 27: $279-418$.

9 Roe L, Hunt P, Bradshaw H, Rayner M. Health promotion interventions to promote bealthy eating in the general population: a review. London: Health Education Authority, 1997.

10 ADA. Position of the American Dietetic Association: Dietary guidance for healthy children aged 2 to 11 years. J. Am. Diet. Assoc. 1999; 99: 93-101.

11 Nicklas TA, Johnson CC, Farris RP, Rice RR, Lyon L, Shi R. Development of school-based nutrition intervention for high school students: Gimme 5. Am. J. Health Prom. 1997; 11: 315-22.

12 Luepker RV, Perry DL, McKinlay SM, Nader PR, Parcel GS, Stone EJ, Webber LS, Elder JP, Feldman HA, Johnson CC. Outcomes of a field trial to improve children's dietary patterns and physical activity: the Child and Adolescent Trial for Cardiovascular Health (CATCH). JAMA 1996; 275: 76876.

13 Perry CL, Bishop DB, Taylor G, Murray DM, Mays RW, Dudovitz BS, Smyth M, Story M. Changing fruit and vegetable consumption among children: The 5-a-Day Power Plus Progam in St. Paul, Minnesota. Am. J. Publ. Health 1998; 88: 603-9.

14 Nicklas TA, Johnson CC, Myers L, Farris RP, Cunnigham A. Outcomes of a high school program to increase fruit and vegetable consumption: Gimme 5-A fresh nutrition concept for students. J. Sch. Health 1998; 68: 248-53.

15 Reynolds KD, Franklin FA, Binkley D, Raczynski JM, Harrington KF, Kirk KA, Person S. Increasing the fruit and vegetable consumption of fourth-graders: results from the High 5 project. Prev. Med. 2000; 30: 309-19.

16 WHO. Ottawa Charter for Health Promotion. Health Promotion 1986; 1: iii-V.

17 WHO. European Network of Health Promoting Schools. A joint WHO-CE-CEC Project. Copenhagen: WHO-Euro, 1993.

18 Dixey R, Heindl I, Loureiro I, Pérez-Rodrigo C, Snel J, Warnking P. Healthy eating for young people in Europe. Nutrition education in Health Promoting Schools. Copenhagen: European Network of Health Promoting Schools, 1999.

19 Aldinger CE, Jones JT. Healthy Nutrition: An essential element of a Health-Promoting School. WHO Information 
Series on School Health. Document four. Geneva: WHO, 1998.

20 Allensworth D, Wyche J, Lawson E, Nicholson L, eds. Defining a comprehensive school health program: an interim statement. Washington DC: National Academy Press, 1995: 2.

21 ADA Statement. Promoting healthy eating behaviors: The role of school environments. Washington DC: USDA, Food, Nutrition and Consumer Services, 1999.

22 CDC. Guidelines for school health programs to promote lifelong healthy eating. J. Sch. Health 1997; 67: 9-26.

23 US Department of Health and Human Services. Centers for Disease Control and Prevention, CDC. SHI. School Health Index for physical activity and bealthy eating. A selfassessment and planning guide. Elementary school. Atlanta 2000.

24 US Department of Health and Human Services. Centers for Disease Control and Prevention, CDC. SHI. School Health Index for physical activity and healthy eating. A selfassessment and planning guide. Middle school/High school. Atlanta 2000.

25 Yngve A, Sjöström M. Breastfeeding in countries of the European Union and EFTA; Current and proposed recommendations, rationale, prevalence, duration and trends. Public Health Nutrition (ibid).

26 Yngve A, Sjöström M. Breastfeeding determinants and a suggested framework for action in Europe. Public Health Nutrition (ibid).

27 King A, Wold $\mathrm{B}$, Tudor-Smith $\mathrm{CH}$, Harel Y. The health of the youth: a cross-national survey. A report of the 1993-94 survey of health behaviour in school-aged children: a WHO cross-national study. Copenhague: World Health Organization Regional Office for Europe, 1996.

28 Riddoch C, EdwardS D, Froberg K, Page A, van Mechelen W, Andersen LB, Sjöström M, Steen Hansen H, Ekelund U, Wedderkopp N, Poortvliet E, Yngve A. for the European Youth Heart Study team. The European Youth Heart Study cardiovascular disease risk factors in children: rationale and design. Public Health Nutrition In press.

29 In: Serra Majem Ll, Aranceta J, eds. Desayuno y equilibrio alimentario. Estudio enKid. Barcelona: Editorial Masson, 2000.

30 Stockley L. The promotion of healthier eating: a basis for action. London: Health Education Authority, 1993.

31 Andrien M, Closset A, Cotelle B, Green J, Halbardier V, Heindl I, Loureiro I, Maree M, Pérez-Rodrigo C, Snel J, Tones K. Planning and evaluating nutrition education in schools. A guide. Liége (Belgium): CERES, 1998.

32 Perez-Rodrigo C, Aranceta J. School-based nutrition education: Lessons learned and new perspectives. Public Health Nutrition in press.

33 Reynolds KD, Franklin FA, Leviton LC, Maloy J, Harrington KF, Yaroch AL, Person S, Jester P. Methods, results and lessons learned from process evaluatiom of the high 5 school-based nutrition intervention. Health Educ. Behav. 2000; 27: 177-86.
34 Pérez-Rodrigo C, Aranceta J. Nutrition education for schoolchildren living in a low-income urban area in Spain. J. Nutr. Educ. 1997; 29: 267-73.

35 Tones BK, Dixey R, Green J. Process indicators at the local level. Part B. Developing and evaluating the curriculum of the Health Promoting Schools. Brussels: Commission of the European Communities. World Health Organization. Council of Europe. Université Libre de Bruxelles, 1997: 1-34.

36 Aranceta J, Pérez Rodrigo C. Consumo de alimentos y estado nutricional de la población escolar de Bilbao. Guías alimentarias para la población escolar. Bilbao: Area de Salud y Consumo Excmo Ayuntamiento de Bilbao, 1996.

37 Raizman DJ, Montgomery DH, Osganian SK, Ebzery MK, Evans MA, Nicklas TA, Zive MM, Hann BJ, Snyder MP, Clesi AL. CATCH: food service program process evaluation in a multicenter trial. Health Educ Q 1994; (Suppl 2): S51-71.

38 Olson CM. Inservice preparation in nutrition education for professionals and paraprofessionals. J. Nutr. Educ. 1995; 27 : 347-54.

39 Ross JG, Luepker RV, Nelson GD, Saavedra P, Hubbard BM. Teenage Health Training Modules: Impact of teacher training on implementation and student outcomes. J. Sch. Health 1991; 61: 31-4.

40 Kirby D. Comprehensive school health and the larger community: Issues and a possible scenario. J. Sch. Health 1990; 60: 170-7.

41 Johnson CC, Osganian SK, Budman SB, Lytle LA, Barrera EP, Bonura SR, Wu MC, Nader PR. CATCH: Family process evaluation in a multicenter trial. Health Educ Q 1994; (Suppl 2): 91-106.

42 Hearn MD, Bigelow C, Nader PR, Stone E, Johnson C, Parcel G, Perry CL, Luepker RV. Involving families in cardiovascular health promotion: the CATCH Feasibility Study. J. Health. Educ. 1992; 23: 22-31.

43 Crockett SJ, Perry CL, Pirie P. Nutrition intervention strategies preferred by parents: Results of a marketing survey. J. Nutr. Educ. 1989; 21: 90-4.

44 Story M, Mays RW, Bishop DB, Perry CL, Taylor G, Smyth M, Gray C. 5-a-day Power Plus: process evaluation of a multicomponent elementary school program to increase fruit and vegetable consumption. Health Educ. Behav. 2000; 27: $187-200$.

45 Nader PR, Sellers DE, Johnson CC, Perry CL, Stone EJ, Cook KC, Bebchuk J, Luepker RV. The effect of adult participation in a school-based family intervention to improve children's diet and physical activity: the Child and Adolescent Trial for Cardiovascular Health. Prev. Med. 1996; 25: 455-64.

46 Gortmaker SL, Cheung LW, Peterson KE, Chomitz G, Cradle JH, Dart H, Fox MK, Bullock RB, Sobol AM, Colditz G, Field $\mathrm{AE}$, Laird $\mathrm{N}$. Impact of a school-based interdisciplinary intervention on diet and physical activity among urban primary school children: Eat Well and Keep Moving. Arch. Pediatr. Adolesc. Med. 1999; 153: 975-83. 